\title{
Obstetric emergencies in the maternity ward of the Ignace Deen national hospital CHU of Conakry: sociodemographic, therapeutic and maternal fetal prognosis aspects
}

\author{
Ibrahima S. Balde*, Ousmane Baldé, Ibrahima Sylla, \\ Ibrahima T. Diallo, Alhassane I. I. Sow, Alpha B. Barry, Thierno M. D. Bah
}

Department of Obstetrics and Gynecology, Service Maternite Hospital National Ignace Deen, University Gamal Abdal Nasser, Conarky, Guinea

Received: 26 September 2020

Accepted: 03 November 2020

\section{*Correspondence:}

Dr. Ibrahima S. Baldé,

E-mail: baldeisory@yahoo.fr

Copyright: $(\odot$ the author(s), publisher and licensee Medip Academy. This is an open-access article distributed under the terms of the Creative Commons Attribution Non-Commercial License, which permits unrestricted non-commercial use, distribution, and reproduction in any medium, provided the original work is properly cited.

\section{ABSTRACT}

Background: Despite government efforts to reduce maternal mortality, the risk of a woman dying from obstetric complications is about one in six in the poorest regions of the world compared to one in thirty thousand in North Europe. The objective was therefore to describe the clinical socio-demographic aspects and to establish the maternal and fetal prognosis of obstetric emergencies.

Methods: This was a descriptive cross-sectional prospective study over a 6-month period from January 1 to June 30, 2020 carried out at the maternity ward of the Ignace Deen national hospital (Conakry university hospital) in Guinea. The study looked at a continuous series of 662 obstetric emergency cases.

Results: The frequency of admission of obstetric emergencies was $22.62 \%$. They concerned young women (29.5 years old) on average, first-time mothers $(53.32 \%)$, with low income professional activities, evacuated from a peripheral maternity unit $(63.14 \%)$, no schooling $(44.9 \%)$, married $(92.3 \%)$, using the more often a means of public transport $(66.5 \%)$ and whose pregnancies were poorly monitored $(63.9 \%)$. Fetal emergencies were dominated by acute fetal distress $(91.3 \%)$ and maternal emergencies were dominated by hypertensive emergencies (pre-eclampsia and eclampsia $37.44 \%$ ) followed by hemorrhagic emergencies (last trimester hemorrhage and postpartum hemorrhage $34.34 \%)$. Pregnant and parturient women were more frequently admitted to labor $(62.7 \%)$ and gave birth more frequently by caesarean section $(86.70 \%)$. the staff reacted promptly to make a treatment decision in $75.5 \%$ of cases within fifteen minutes. emergency procedures were performed in less than fifteen minutes in almost all cases $(97.4 \%)$, specific treatment was carried out in less than an hour in the majority of cases $(68.3 \%)$. The maternal case fatality rate was $4.1 \%$ with the main cause of death being hemorrhagic shock of $51.8 \%$. The stillbirth rate was $17.4 \%$.

Conclusions: The anticipation of emergency obstetric care (SOU) and close collaboration between the obstetrician, the anesthesiologist-resuscitator are essential in the management of obstetric emergencies.

Keywords: Obstetric emergencies, Socio-demographic, Clinical, Treatment, Prognosis, Guinea

\section{INTRODUCTION}

Pregnancy is a happy and natural event which, however, may require urgent consultations or interventions. Pregnancy, if it is carried out properly, leads to a live birth and constitutes for women a criterion of social valorization.

However, for thousands of women, the outcome of pregnancy can be fatal. 
Safe motherhood is one of the dearest dreams of all women, and making this dream come true is the primary duty of all obstetric care providers.

Obstetric emergencies are dramatic clinical situations involving the maternal and/or fetal vital prognosis in the short term. These are all circumstances which, by their occurrence or their discovery, induce or suggest a functional or vital risk for the mother and the fetus. if medical or surgical action is not taken immediately. They are a major public health concern in the world, especially in developing countries like ours, Guinea.

WHO estimates that each year around the world, at least half a million women die from obstetric complications and $3 \%$ of some 120 million children born each year experience acute fetal distress and about 90,000 of them. they die immediately from this respiratory distress. ${ }^{2-4}$ The vast majority of these deaths have occurred in low-and middle-income countries where efforts have been made to improve delivery rates in health facilities and despite these efforts, 60 million births are currently taking place outside of health facilities. health structures including 52 million without qualified assistance. ${ }^{5}$

Complications of pregnancy, difficult to predict, usually appear early in childbirth and often require timely management to avoid death and severe morbidity. ${ }^{6}$

Numerous studies on maternal mortality have shown that the quality of obstetric services, as well as the provision of timely and adequate care for obstetric emergencies, are essential to reduce maternal morbidity and mortality in institutions. $^{7}$

These obstetric emergencies are represented in particular by hemorrhages, arterial hypertension and its complications, obstructed labor, infections and acute fetal distress; maternal mortality and stillbirth are the dramatic results of these complications. The importance and severity of the complications are primarily related to the consequences of illiteracy, lack of health education, low socioeconomic level, insufficient medical infrastructure as well as a lack of qualified personnel. ${ }^{8,9}$

These conditions are typical of developing countries. Emergencies in the labor room remain frequent in developing countries like ours.

They are responsible for high fetal-maternal morbidity and mortality despite the progress made in many countries to improve maternal care, and the majority of African women still do not have sufficient access to these care services. obstetrics. Lack of knowledge of the physiological mechanisms of childbirth, delayed evacuation, poor monitoring of pregnancy and noncompliance with monitoring of labor by the partograph are all factors found in the occurrence of these emergencies. $^{2-10}$
Thus, the objective of the present study was to describe the socio-demographic, clinical, therapeutic aspects and to establish the maternal and fetal prognosis of obstetric emergencies.

\section{METHODS}

This was a descriptive cross-sectional prospective study over a period of 6 months from January 1 to June 30, 2020 carried out at the maternity ward of the Ignace deen national hospital (Conakry university hospital) in Guinea.

The study covered a continuous series of 662 obstetric emergency cases.

Inclusion and non-inclusion criteria prevailed in the selection of the sample. Were included in the study all the women admitted for an obstetric pathology involving the maternal and/or fetal prognosis requiring immediate treatment and having agreed to participate in the study and were not included in the study, women admitted to the service whose condition does not require immediate treatment and who's maternal and / or fetal prognosis was not involved.

Sampling was done by the study population consisted of all the women admitted for an acute pathology occurring during pregnancy, during childbirth or in the 42 days following and for whom a precise diagnosis and rapid treatment were necessary in order to preserve the prognosis. maternal and/or fetal vital. The sampling was exhaustive.

We followed the patients from their admission to the maternity hospital until their discharge.

Data was collected from patient records, childbirth registers, on-call reports and the operating report register.

The variables studied were: socio-demographic characteristics, clinical and therapeutic data and those of the evolution of the prognosis.

\section{RESULTS}

\section{Frequency}

During the study period we recorded 2,927 obstetric consultations including 662 cases of emergencies, ie a frequency of $22.62 \%$.

\section{Sociodemographic characteristics}

Age: The average age is $25.9 \pm 6.1$ years with extremes of 14 and 44 years. The most represented age group was that of 26-30 years with respectively 27.3 and $27.0 \%$.

Profession: Several professional categories had been identified: liberal (40.4\%), housewife (28.0\%), high/student $(23.0 \%)$ and salaried $(8.6 \%)$. 
Level of education: The majority of women were out of school, i.e. $(44.9 \%)$. Status matrimonial: the majority of women live in a matrimonial home (married), i.e. $92.3 \%$.

Table 1: Distribution of women by mode of admission and reason for evacuation.

\begin{tabular}{|lll|}
\hline Setting & Frequency & Percentage $(\%)$ \\
\hline Homes & 244 & 36.86 \\
\hline Evacuated & 418 & 63.14 \\
\hline $\begin{array}{l}\text { Immediate } \\
\text { postpartum } \\
\text { hemorrhage }\end{array}$ & 25 & 5.98 \\
\hline Dystocia & 51 & 12.20 \\
\hline Eclampsia & 56 & 13.39 \\
\hline Placental hematoma & 95 & 22.72 \\
\hline $\begin{array}{l}\text { Severe pre- } \\
\text { eclampsia }\end{array}$ & 53 & 12.67 \\
\hline Placenta previa & 22 & 4.80 \\
\hline Cord procidence & 5 & 1.20 \\
\hline Acute fetal pain & 113 & 27.04 \\
\hline
\end{tabular}

\section{Structures of origin of patients}

Most of the evacuated patients come from municipal health centers (maternity level 2), i.e. $44.02 \%$ followed by private clinics with $39.32 \%$.

Means of transport used: The most frequently used means of transport was public transport (66.50\%) followed by personal car with $21.30 \%$.

Residence: The patients most frequently came from the municipalities of Ratoma (35.5\%) and Matoto (30.5\%).

Parity: First-time mothers were the most frequently represented, i.e. $53.32 \%$, followed by pauciparae $(29.2 \%)$

Prenatal consultation $(A N C)$ : the average number of prenatal consultations was 2.83 with extremes of 0 to 6 . Pregnancies were more frequently followed in health centers (maternity level 1) or $55.13 \%$ followed by medical centers communities $(28.1 \%)$.

\section{Clinical data}

History of cesarean section: It was noted in 435 out of 662 patients $(65.71 \%)$.

Mode of delivery: Delivery was carried out in the majority of cases by cesarean section, i.e. $86.70 \%$ against $11.9 \%$ for vaginal delivery and $1.40 \%$ after laparotomy for uterine rupture.

Type of vaginal birth: The vaginal delivery was predominantly eutocic $(75.95 \%)$ compared with $24.05 \%$ obstructed delivery.
Table 2: Distribution of patients by type of emergency.

\begin{tabular}{|l|l|l|}
\hline Type of emergency & Frequency & Percentage (\%) \\
\hline Fetal & 230 & 34.74 \\
\hline $\begin{array}{l}\text { Obstructed } \\
\text { présentations }\end{array}$ & 14 & 6.1 \\
\hline Cord procidence & 6 & 2.6 \\
\hline Acute fetal pain & 210 & 91.3 \\
\hline Kindergarten & 585 & 88.36 \\
\hline Dystocia & 49 & 8.37 \\
\hline Infection & 4 & 0.70 \\
\hline Anémia & 97 & 16.58 \\
\hline Pre-eclampsia & 143 & 24.44 \\
\hline Eclampsia & 76 & 13.00 \\
\hline $\begin{array}{l}\text { Retro-placental } \\
\text { hematoma }\end{array}$ & 121 & 20.68 \\
\hline Placenta previa & 40 & 6.83 \\
\hline Uterine rupture & 9 & 1.53 \\
\hline $\begin{array}{l}\text { Postpartum } \\
\text { hémorrage }\end{array}$ & 31 & 5.30 \\
\hline $\begin{array}{l}\text { Pre-rupture } \\
\text { syndrome }\end{array}$ & 15 & 2.56 \\
\hline
\end{tabular}

Table 3: Admission period.

\begin{tabular}{|ll|l|}
\hline Admission period & Frequency & Percentage (\%) \\
\hline Pregnancy & 189 & 28.5 \\
\hline Work phase & 414 & 62.7 \\
latency phase & 304 & 45.9 \\
\hline Active phase & 111 & 16.8 \\
\hline Post partum & 58 & 8.8 \\
\hline Total & 662 & 100 \\
\hline
\end{tabular}

\section{Supported}

Table 4: Distribution of patients according to the existence or not and type of obstetric or surgical intervention performed.

\begin{tabular}{|l|l|l|}
\hline Setting & Frequency & Percentage (\%) \\
\hline No & 146 & 22 \\
\hline Yes & 516 & 78 \\
\hline $\begin{array}{l}\text { Caesarean } \\
\begin{array}{l}\text { Instrumental } \\
\text { extraction }\end{array}\end{array}$ & 583 & 90.0 \\
\hline $\begin{array}{l}\text { Hemostatic } \\
\text { hysterectomy }\end{array}$ & 11 & 1.7 \\
\hline Uterine revision & 38 & 0.2 \\
\hline Suture of soft parts & 16 & 5.9 \\
\hline Cerix: $(0.77 \%) ;$ vagin & $3(0.58 \%) ; p$ & 2.2 \\
\hline
\end{tabular}

Cervix: 4 (0.77\%); vagina: 3 (0.58\%); perinea: 9 (1.74\%)

Need for blood transfusion: Of the 662 obstetric emergency cases, 144 patients had received a blood transfusion, i.e. $21.8 \%$.

Time limit for therapeutic decision-making: It was less than or equal to 15 minutes in the majority of cases $(75.5 \%)$. 
Table 5: Distribution of patients according to the evolution of the course of childbirth.

\begin{tabular}{|lll|}
\hline Setting & Frequency & Percentage (\%) \\
\hline Simple & 438 & 66.16 \\
\hline Complicated & 224 & 33.84 \\
\hline Anemia & 157 & 70.08 \\
\hline Eclampsia & 16 & 7.14 \\
\hline Death & 27 & 12.05 \\
\hline $\begin{array}{l}\text { Arterial } \\
\text { hypertension }\end{array}$ & 8 & 3.5 \\
\hline Parietal lesions & 16 & 7.14 \\
\hline
\end{tabular}

Deadline for emergency actions: It was less than 15 minutes in almost all cases $(97.4 \%)$.

Specific treatment time: It was less than or equal to 1 hour in the majority of cases $(68.3 \%)$. It was between $1-2$ hours in $26.50 \%$ of cases.

Medical treatment: It was dominated by antibiotic therapy (67.02) followed by antihypertensive treatment $(17.8 \%)$ and blood transfusion (15.18\%).

\section{Prognosis}

Maternal prognosis: We recorded 27 cases of maternal death out of 2,655 live births, i.e. a case fatality rate of $4.1 \%$ and a ratio of 922.44 per 100,000 live births. The causes of death were dominated by hemorrhagic shock $(51.8 \%)$ followed by eclamptic coma $33.3 \%$.

Neonatal prognosis: Status of the newborn: the newborn was alive and well in $43.3 \%$, presented neonatal distress in $39.3 \%$ and stillborn in $17.4 \%$.

Neonatal complications: they were dominated by death (43.4\%) followed by respiratory distress (22.6\%) and prematurity $(19.6 \%)$.

Type of perinatal mortality: antepartum mortality was the most frequently encountered $(85.2 \%)$ against $8.7 \%$ early neonatal mortality and $6.1 \%$ perpartum fetal mortality.

\section{DISCUSSION}

\section{Frequency}

This study reveals a high frequency of obstetric emergencies $(22.62 \%)$.

This frequency is comparable to that of Bagnan et al in Cotonou in Benin reporting $21.7 \%$ obstetric emergencies. ${ }^{11}$ On the other hand, it is lower than that reported by Lokossou et al. ${ }^{12}$ in the same country (chu of Oueme plateau in Benin) or $34.8 \%$ and that of Boyoma et al in Congo reporting $29.6 \%$ of obstetric emergencies. ${ }^{13}$ Our frequency is on the other hand higher than that reported by Moutounbo et al in Congo or $6.03 \% .{ }^{14}$
The relatively high frequency in our series could be explained by the fact that the maternity unit of the Ignace deen national hospital is currently the only functional referral center for maternal health receiving obstetric emergencies in the Guinean capital (city of Conakry) and neighboring prefectures. These reported frequencies show that obstetric emergencies generally remain a public health problem affecting mainly developing countries and testifying to the level of the health system in these countries.

\section{Sociodemographic characteristics}

The average age of our patients and the most represented age groups were consistent with data from the international literature Tshonga et al in Gabon, Oliveira et al. ${ }^{15,16}$ in Brazil. The average age found in our series corresponds to the period of intense obstetric activity in accordance with data in the literature. ${ }^{17,18}$

Compared to the socio-professional layer, our results dominate those of Blaise et al at the university of Parakou in Benin. ${ }^{19}$ These low-income women are subjected to stress and significant physical exertion, thus promoting the rapid onset of complications during pregnancy. In addition, their state of no schooling is a source of ignorance with regard to the rules for monitoring pregnancies with the end result of the abandonment of prenatal consultations because of the onset and late discovery of complications during pregnancy.

The predominance of married women in our series $(92.3 \%)$ would be due to the cultural and religious context of our country, which hardly admits any conception outside marriage. On the other hand, the presence of single people could be explained by the lack of prenatal care due to the abandonment by their family.

More than half of the patients in our series were evacuated $(63.14 \%)$ with non-medical transport in $87.80 \%$ of cases. This high rate of obstetric evacuation in our series shows that high-risk pregnancies are initially followed in peripheral maternities (health centers and medico-communal centers) and are evacuated only for complications, unlike the organization of the health system which recommends at-risk pregnancies must be taken care of in referral maternity hospitals. This contact poses the problem of revitalizing the referral and counterreferral system in our regions.

Unlike the evacuated cases, a non-negligible rate $(36.86 \%)$ of obstetric emergencies were admitted to the hospital coming directly from their home, which would contribute positively to reducing the first two longawaited delays in the risk management of obstetric emergencies; and the most frequently found reason for evacuation was acute fetal distress $(27.04 \%)$ followed by retroplacental hematoma, eclampsia and dystocia with $22.72,13.20 \%$ and 12 respectively, 20\%. The high frequency of acute fetal distress in our series could be 
explained by the delay in evacuating patients in transport, in decision-making and in management. That of retroplacental hematoma, eclampsia and obstructed labor could be linked to the poor quality of prenatal follow-up and the management of deliveries.

The high influx of patients from the communes of Ratoma and Matoto is linked to the fact that these two communes are the most populated in the capital on the one hand and on the other hand the lack of health structures in these localities and insufficient qualified personnel.

The first-time mothers were the most frequently represented, i.e. $53.32 \%$, followed by the pauciparous with $29.02 \%$. At Brazzaville CHU, admissions to obstetric emergencies were dominated by first-time mothers $(42 \%){ }^{18}$ In their series, primiparity was associated with preeclampsia and eclampsia in the majority of admitted cases. ${ }^{18}$ In Benin, multiparas $(34.59 \%)$ and first-time mothers $(27.83 \%)$ were in the majority. ${ }^{17}$ So, the gravido-puerperium of this category of pregnant women is punctuated by many obstetric problems due to the immaturity of the body and the inexperience associated with early marriages. ${ }^{1,20}$ The average number of antenatal consultations found in our $2.83 \%$ series is clearly below the number required by the WHO, recommending 8 antenatal contacts per pregnancy. ${ }^{21}$

Admittedly, prenatal follow-up constitutes an effective preventive activity that makes it possible to improve the outcome of pregnancies and the early detection of certain pathologies linked or associated with pregnancy and prevent their progression to more serious situations; but their number is not enough, we must add to this the quality for better prenatal monitoring.

\section{Clinical data}

\section{History of cesarean section}

It was noted in $65.71 \%$ of patients. High frequency compared to that reported by Blaise et al in Benin $(11.4 \%)$. This difference could be explained by our cesarean section rate $(86.70 \%)$ under the influence of the influx of scarred uterus. ${ }^{19}$

In Bouaké in the ivory coast, scarred uteri were considered to be a factor in uterine rupture. ${ }^{20}$ Lansac, for his part, estimates the relative risk of uterine rupture and placenta previa at 5 after surgery on the uterus. ${ }^{22}$ In a multivariate study in Burkina Faso using logistic regression, six risk factors were retained as being associated with the occurrence of obstetric emergencies among them the history of cesarean section multiplied the risk of severe maternal morbidity by 7 (relative risk $=6$, 9). ${ }^{23}$ Our results are superimposable on those of the majority of developing countries.

\section{Type of obstetric emergency}

The causes of obstetric emergencies are the same from study to study. In our series maternal emergencies predominated over fetal emergencies, i.e. 88.36 versus $34.74 \%$.

Fetal emergencies were predominated by acute fetal distress or $91.3 \%$ and maternal emergencies were dominated by hypertensive emergencies (preeclampsia and eclampsia) with $37.44 \%$ followed by hemorrhagic emergencies (last trimester hemorrhage and postpartum hemorrhage.) with $34.34 \%$. Our results are close to those of Bagnan et al in Benin, reporting that hemorrhagic and hypertensive emergencies and acute fetal distress were predominant with $36 \%$ respectively; 24.5 and $15.3 \% .^{11}$

With regard to certain specific causes, the frequency of obstructed labor observed in our department $(8.37 \%)$ is lower than that reported by Blaise et al in Benin (32.1\%). ${ }^{19}$ In this etiological group, pelvic abnormalities occupied the first place. This observation highlights the poor quality of prenatal follow-up and the monitoring of labor associated with insufficient coverage of qualified personnel capable of detecting high-risk pregnancies and thus avoiding serious obstetric evacuations linked to obstructed labor. In our series, hemorrhages in the last trimester of pregnancy were the first etiology of hemorrhagic emergencies, a different result from that of Blaise et al in Benin, reporting a predominance of postpartum hemorrhage. ${ }^{19}$ All these hemorrhagic emergencies have the particularity of often involving the vital prognosis of the mother and the fetus because of the extent of the hemorrhage that it causes, resulting in the installation of a state of shock.

In general, the management of these hemorrhagic emergencies is often confronted with the unavailability of blood product and the lack of financial resources of the patients. High blood pressure during pregnancy is a global public health problem and a major risk factor for mortality during pregnancy. In the absence of well-coded management, it progresses to major complications also found in our series. Acute fetal distress is vital for the fetus within hours or even days of the onset of hypoxia. It can be without serious consequences, or lead to fetal death or brain damage with sequelae. It requires rapid and adequate management.

\section{Mode of delivery}

The delivery prognosis depends mainly on the nature of the obstetric emergency in progress and the associated history, most of which appear to be real risk factors. In the present study, in $86.70 \%$ of cases; the delivery ended with a caesarean. A rate similar to ours was reported by Mutombo et al in Congo (85.53\%). ${ }^{14}$ Cesarean section is a surgical act to save the maternal fetus and is the most frequent outcome of childbirth in the majority of obstetric emergencies in the labor room. In Cotonou the rate of 
emergency caesarean section was $57.26 \%$ and at the Brazzaville CHU the rate was $46 \%{ }^{17,18}$ Thus, the highest rate of cesarean section is observed in our series. This disparity in results could be explained by the diversity of emergencies depending on the country, the means and quality of care available as well as the habits of each obstetrician. It should be noted all the same, that these rates are still high in Africa on the sidelines of WHO recommendations setting them outside of $15 \% .^{24}$

\section{Admission period}

The period of labor was the most frequently encountered at $62.7 \%$ followed by emergencies during pregnancy $28.5 \%$. These results could be explained on the one hand by the method of admission of these patients, most of whom were evacuated after having stayed in peripheral structures; on the other hand, that she came to the hospital when she noticed uterine contractions.

\section{Supported}

The management of obstetric emergencies is well codified today and the analysis of the results of our study shows that the recommendations were generally well followed. However, the complications observed both in the delivery room and in the operating room are linked not to a weakness in the care system, but to the seriousness of the clinical condition of the patients admitted, often with multiorgan disease. therapeutic attitude was based on clinical data. In order to reduce fetal and maternal mortality, an operating kit system was put in place to deal with the emergency as soon as it arose. Thus $90 \%$ of our patients were caesarean and $21.8 \%$ received blood transfusion. Although the therapeutic attitude depends on the maternal-fetal prognosis, it appears that the cesarean section is the first therapeutic indication in the event of obstetric emergency in the constant concern of maternal and fetal rescue.

\section{Support times}

As for the delays in the various stages of administration of obstetric care, the staff reacted quickly to make a treatment decision in the majority of cases $(75.5 \%)$ in less than 15 minutes. Emergency procedures were performed early in our series (in less than 15 minutes) in most cases $(97.4 \%)$. Specific treatment was in less than an hour in the majority of cases $(68.3 \%)$ the importance of access to quality obstetric care as a pillar in the reduction of maternal mortality in our developing countries. development is now demonstrated by several studies.

\section{Prognosis}

Maternal prognosis: Maternal deaths were recorded in 27 cases out of 2,655 live births, for a maternal case fatality rate of $4.1 \%$ and a maternal death ratio of 922.44 per 100,000 live births. This case fatality rate is much higher than that of Bagnan et al in Benin reporting 2.3\%.11
Obstetric hemorrhagic emergencies constitute a specific situation which requires immediate multidisciplinary management in which obstetricians, intensive care anesthetists and interventional radiologists are involved. Obstetric hemorrhages have several characteristics: Their severity is the main cause of maternal death in the world representing $24 \%$ of cases, neither predictable nor avoidable 8 to 9 deaths in 10 seem to be directly linked to inadequate care. ${ }^{27}$

Neonatal prognosis: It was severe during this study with $17.4 \%$ stillbirth. Giving birth in an emergency situation thus multiplies the risk of stillbirth by more than 6 in our series.

\section{Limitations}

The only one recorded is the incorrect filling of a few files following the overload of work to be done by the doctors on call (in flow especially at night).

\section{CONCLUSION}

This study allowed us to understand that obstetric emergencies constitute a real public health problem in our environment because of the very reserved prognosis that they impose on the mother-child couple. The etiologies are diverse, dominated especially by hemorrhagic emergencies, hypertensives and obstructed labor. Reducing the morbidity and mortality associated with obstetric emergencies requires improving the quality of care, from educating patients to consult early to improving the technical platform and medical inputs.

Funding: No funding sources Conflict of interest: None declared

Ethical approval: The study was approved by the Institutional Ethics Committee

\section{REFERENCES}

1. Bayoma BM. Study of the frequency of obstetric emergencies at the Kamina referral hospital, public health licenses. Kamina University DRC. 2011;55.

2. Coulibaly D. Epidemio clinical study of obstetric emergencies at the reference health center of commune IV about 293 cases thesis, Bamako university, faculty of medicine Pharmacy and odontostomatology, Mali. 2007.

3. Oms. Summary report of the launch of the guideline for clinical practice in emergency obstetric and neonatal care in Africa. Bamako, Mali. 2009.

4. Foun L, Lokossou, Fayoni EB, Yacoubi M. Preventable maternal mortality in a hospital environment in a department in Benin. Black Afri Med. 2000;47(1).

5. Walker D, Cohen S, Fritz J, Olivera M, LamadridFigueroa H, Greenberg-Cowan J et al. Team training in obstetric and neonatal emergencies using highly 
realistic simulation in Mexico, impact on process indications, biomed central. 2014,14:367-78.

6. Pacha O, Goldenberg RL, Mc Clure ME, Saleem S, Goudars S, Althabe $\mathrm{F}$ et al. Communities birth attendants and health facilities a continuum of emergency maternal and new born care (the global network's emonc triol). Bio Med Cent Pregn Chi Birth. 2010;10;82-91.

7. Fritz J, Lamadrid-Figueroa H, Angels G, Montoya A, Walker D. Health providers pass knowledge and abilities acquired by training in obstetric emergencies to their peers; the average treatment on the treated effect of pronto on delivery attendance in Mexico. Biomed Central Pregn Child Bi. 2018;18:232-40.

8. Bouvier-Colle MH, Philibert MM. Epidemiology of maternal mortality in France, frequency and characteristics. Réanimation. 2007;16:358-65.

9. Marianne P, Botsbras F, Mariehelene Bouvier C. Epidemiology of maternal mortality in France, frequency, factors and causes. Weekly epidemiol bulletin France. 2006;50.

10. Dissa L. Epidemiological-clinical study of obstetric emergencies at the reference health center of commune V from 2002-2003 about 1265 cases, thesis, University of Bamako, faculty of medicine, pharmacy and odonto stomatology Mali. 2005.

11. Bagnan TJA, Lokossou MSHS, Agemon TC, Yessoufou MMAO, Adisso S, Lokossou A et al. Obstetric emergencies (CUGO) of the national hospital and university center Hubert Koutoukou Maga (CNH HKM) in Cotonou: epidemiological and prognostic aspects. SAGO J. 2017;2(18);1-10.

12. Lokossou MSH, Agoudjobiom, Toguifode V, Adissos, Ali A et al. The etiologies of obstetric emergencies in the maternity ward of the departmental university hospital of L'ouemé-plateau (CHUDOP) in BENIN. J Bio Clin Soc. 2016;27;528.

13. Masala BB. study of the frequency of obstetric emergencies at the general referral hospital of Kamina DRC University of Kamina DRC license in public health. 2011.

14. Mutombo C. Mumbamukandilaa, Mikenji BJ.: Profile and prognosis of obstetric emergencies in the labor ward of the bonzola maternity unit in MbujiMayi. Mali med. 2015;30(4):65-73.

15. Tsonga MS, Akovo L, Ngou, Mve-Ngou JP, Meye JF. Risk factors for Libreville eclampsia (GABON), case-control studies, study book, and Frenchspeaking/health Res. 2006;16:197-200.

16. Oliveira Jr FC, Costa ML, Cecahi JG, Silva PJL, Surita FG. Maternal morbidity and near miss associated with maternal age; the innovation approach of the 2006 BRAZILIAN demographic health survey clinics. 2013;68(7):922-7.
17. Aguemon TC, Denakpo J, Adisho S, Possi ME, DE Sonza J. Maternal and perinatal mortality linked to the obstetric references of CUGO of the HKM of Cotonou. Except RAMUR tome. 2012;17(1):1-6.

18. Otiobanda GF, Mahoungou-Guimbi KC, Itona $\mathrm{C}$, Ellenge Mbolla FB, Soussa RG. morbidity and mortality during pregnancy and surgery in a multipurpose intensive care unit. SARAUF ramur tome. 2012;17(2).

19. Blaise AT, Nouessewa, Salifou FM HP, Zounmenon E, Chobli M. Obstetric emergencies at the PARAKOU university hospital in Benin, clinical, therapeutic and progressive aspects. Eur sci J. 2015;11(9):260-72.

20. Kouakou P, Djanhan Y, Doumba Y, Djanhan L, Ouatara M. In Uterine ruptures, epidemiological aspects and maternal fetal prognosis at the Bouake CHU maternity unit, Edition CAMES-sene A. vol 05 Cote d'Ivoire. 2017.

21. OMS. WHO recommendations for prenatal care for a positive pregnancy experience WHO/RHR/16.12. 2016;9.

22. Dumas AM, Bertrand M. Hemorrhage at the start of labor: leads to hold. Lansac J. Body G, Perrotin F and Marr and $\mathrm{H}$ (EDS) practice of childbirth, Masson edition, Paris. 2001;303.

23. Ouadraogo C, Testa J, Sondob, Kone B. Analysis of risk factors for severe maternal morbidity in Ouagadougou, Burkina Faso. Black Afr Med. 2001;48.

24. El Béchir M, El Diyans ME. The prevalence of caesarean section at the regional hospital of zonerate, University of Nouakchott. 2011.

25. Organisation mondiale de la sante. Beyond the Numbers, Examining Maternal Deaths and Complications to Reduce Pregnancy Risks Geneva. 2004; 155 .

26. Belghiti A, De Bronwere V, Vanlerberghe W. Monitoring un met obstetric need at district level in morocco. Trop. Med Int Health. 1998;3:584-91.

27. Bouvier-Colle MH, Hetton F. Measurement of maternal mortality. Difficulties and evolution over the past twenty years. In Bouvier-Colle $\mathrm{MH}$, Vamoux N, Bréart G (eds). Maternal deaths in France. Analyzes and prospective. Paris. Inser M. 1994;7-22.

Cite this article as: Baldé IS, Baldé O, Sylla I, Diallo IT, Sow AII, Barry AB, Bah IMD. Obstetric emergencies in the maternity ward of the Ignace Deen national hospital CHU of Conakry: sociodemographic, therapeutic and maternal fetal prognosis aspects. Int $\mathrm{J}$ Reprod Contracept Obstet Gynecol 2020;9:4799-805. 